\title{
Effect of Salinity on Mechanical Behaviour of Well Cement: Application to Carbon Capture and Storage Wells
}

\author{
S.Gowthaman, S.Krishnya and M.C.M. Nasvi
}

\begin{abstract}
Integrity of injection wells play a vital role in the success of carbon capturing storages (CCS) and oil/gas extraction projects. Well cement plays a vital role in ensuring well integrity and the loss of well integrity may be caused due to the down-hole curing conditions. The salinity in the storage reservoirs varies from $0-30 \% \mathrm{NaCl}$ depending on the geological location, and hence a typical well cement is exposed to a range of salinity levels. Therefore, aim of this research was to analyze the mechanical behaviour of cement cured in saline water. Testings such as uniaxial compressive strength (UCS) test, X-Ray Diffraction (XRD) and Scanning Electron Microscopy (SEM) were conducted or well cement cured in different $\mathrm{NaCl}$ brine concentrations (0- 30\%) with various curing periods (7- 45 days). Based on the experimental outcome, it was observed that the strength and the Young modulus of OPC based well cement decreases with salinity levels and with ageing in time. Moreover, SEM test results showed that the $\mathrm{NaCl}$ penetration and deposition into the samples is high at higher salinity levels and longer ageing periods. On the whole, OPC based well cement experiences cement degradation in saline aquifers and hence this should be considered in the design of these wells.
\end{abstract}

Keywords: Brine, Degradation, Salinity, Well cement

\section{Introduction}

Greenhouse gas effect causes many serious problems, such as global warming, environmental pollution and hazardous effects in living beings in this globe. $\mathrm{CO}_{2}$ is the gas that plays a major role in such problems that leads to the dispersion of sustainability of the globe. According to the report of Energy information administration 2003, annual emission of $\mathrm{CO}_{2}$ is 6.5GT/year and it is predicted that 2000 million tons of $\mathrm{CO}_{2}$ increment in 2030 [1]. Therefore, it is very much important to understand how the $\mathrm{CO}_{2}$ reaches the atmosphere. The major $\mathrm{CO}_{2}$ emissions are due to the increasing usage of coal powered plants, petroleum usage and oil recovery. Using low carbon energy sources are eco solutions for this problem but it cannot satisfy the energy requirement in our present situation. Therefore, storing carbon dioxide $\left(\mathrm{CO}_{2}\right)$ in underground wells is considered as the most effective way for long-term, safe and low-cost $\mathrm{CO}_{2}$ sequestration [2, 3]. In Sri Lanka, a coal power plant has been constructed and it is in operation from 2011. As we are facing water scarcity problems due to variations in climatic conditions and rain fall patterns and improper management systems, in the future, we might go for more coal power plants to fulfil our energy requirements. However, there will be a problem related to emission of $\mathrm{CO}_{2}$ due to the combustion of coal. Hence, carbon capture and storage will be useful in this context. Coal seams, saline aquifers and depleted oil/gas reservoirs, deep saline aquifers and unminable coals beds are used for storing captured $\mathrm{CO}_{2}[4]$. Injection wells are widely used not only for $\mathrm{CO}_{2}$ injection but also for the oil and gas extraction projects. Therefore, it is important to ensure cement integrity under various down-hole conditions. The integrity and zonal isolation of injection wells depend on many factors and the major factor is well cement that is used as primary cement for the construction of these wells.

Well cement must be carefully designed to meet demanding requirements such as predictable setting time, high sulphate resistance, high durability, fluid loss control, consistency, low viscosity, low free fluid, and strength [5]. This well cement is categorized according to the American Petroleum Institute (API) specification standards, which has identified 8 classes of cement according to the depth of the well, the temperature and pressure [6].

Generally, API class $G$ \& $H$ cements are commonly used for the construction of injection

Mr. S.Gowthaman, B.Sc. Eng. (Hons.)(Peradeniya), Department of Civil Engineering, University of Peradeniya, Sri Lanka.

Miss. S.Krishnya, B.Sc. Eng. (Hons.)(Peradeniya), Department of Civil Engineering, University of Peradeniya, Sri Lanka.

Eng. (Dr.) M.C.M. Nasvi, B.Sc. Eng. (Hons.) (Peradeniya), Ph.D(Monash), AMIE(Sri Lanka), Lecturer of Civil Enoineering, Department of Civil Engineering, 
wells. However, class $G$ is most preferable for construction [6]. At present, OPC based well cement is used for more than $80 \%$ of the well construction in oil \& gas fields [7, 8]. This primary cement acts as a sealant and prevents fluid communication between various underground fluid-containing layers where the salinity level $(0-30 \%)$ varies from place to place and also varies with depth $[1,7]$. Therefore, the well cement in a injection/production well is exposed to different salinity levels, and this issue affects the actual strength of the OPC based well cement. Hence, mechanical behaviour of the well cement depends on the curing under various salinity levels.

To date, there are few studies $[2,9]$ focusing on oil well cement behaviour in saline water. Lecolier et al [2] studied the strength variation of the API class G cement cured in brine for 400 days at $80^{\circ} \mathrm{C}$. Based on the above study, the strength of the cement decreased with ageing time due to the degradation of C-S-H. Similarly, Xingshan et al [9] studied the mechanical behaviour of class $\mathrm{G}$ cement cured in different $\mathrm{NaCl}$ brine concentrations at two different curing temperatures $\left(93^{\circ} \mathrm{C} \& 160^{\circ} \mathrm{C}\right)$ and they observed that the strength increased with curing time (up to 72 hours) at both temperatures because of the degree of hydration. In addition, they also observed that the strength decreases with the brine concentrations due to the retardation in hydration process in brine. However, there are no studies relevant to the mechanical behaviour of OPC based well cement in brine at average down-hole temperature $\left(50^{\circ} \mathrm{C}\right)$. Therefore, major aim of this research is to study the mechanical behaviour of OPC based well cement cured under different salinity levels for different ageing times. Uniaxial compressive strength (UCS) test, X-Ray Diffraction (XRD) test, Scanning Electron Microscopical (SEM) observation and Energy Dispersive X-ray (EDX) spectroscopy analysis were conducted and results were compared.

\section{Experimental Methodology}

Well cement samples were prepared using Ordinary Portland Cement (OPC) with sulphate resistance. OPC was purchased from Holcim Lanka (Pvt) ltd, Colombo, Sri Lanka. The composition of the OPC with sulphate resistance was obtained from X-Ray Diffraction (XRD) test and the results are given in section 3.1. The cement paste was prepared with a water/cement ratio of 0.44 as it is found to be the optimum based on previous studies $[1,2$, and 10]. Based on the mix design, samples with $50 \mathrm{~mm}$ diameter and $100 \mathrm{~mm}$ height were prepared using PVC moulds as shown in Figure 1. Then they were oven cured at $50^{\circ} \mathrm{C}$ and during the oven curing, top side of the samples was covered with polythene to avoid excessive moisture loss. After 24 hours of curing, the samples were allowed to cool down for another 6 hours in the atmosphere.

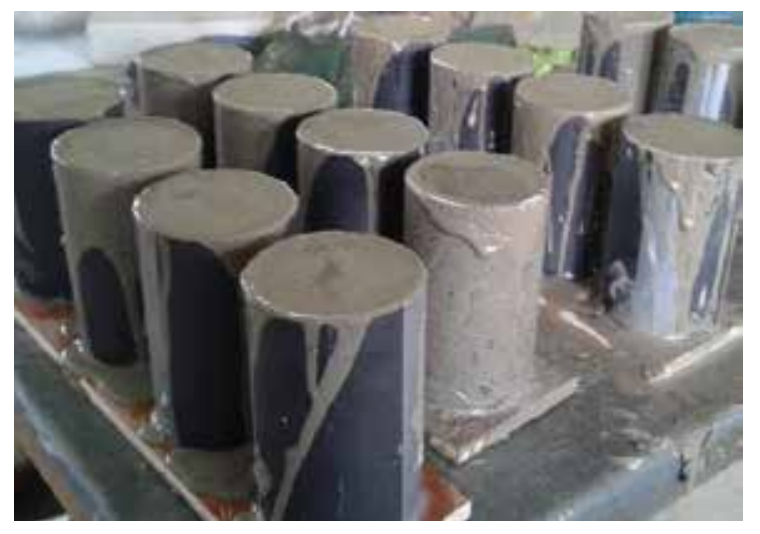

Figure 1 - Casted Samples

The samples were then transferred to the curing containers having different brine concentrations $(0,10,20$ and $30 \% \mathrm{NaCl})$ except the control samples that were used to compare the results. As salinity level varies from $0-30 \% \mathrm{NaCl}$ depending on the geological location $[1,7]$, the above particular brine concentrations were selected to this study. The brine solutions were prepared by mixing $\mathrm{NaCl}$ salt and distilled water in due mix proportions. All the samples were immersed in brine solutions for $7,14,28$ and 45 days prior to the testing. The long term behaviour (400 days) of oil well cement in brine was analysed by Lecolier et al. [2], while the short term behaviour (up to 72 hours) was studied by Xingshan et al. [9]. Since there are limited number of research studies in this area and no research works focusing on the intermediate curing periods, this research work focused on the mechanical behaviour of well cement cured up to 45 days. For each condition three samples were tested to ensure reproducibility.

Uniaxial compressive strength (UCS) test was conducted by using the UCS testing machine with the stress control loading rate of 0.2 $\mathrm{MPa} / \mathrm{sec}$. Samples were machine ground on both the sides using a grinding machine and polished to ensure purely uniaxial loading during the experiment. Further, top surface was capped with sulphur prior to the UCS testing to apply uniform uniaxial loading. 
In addition, Scanning Electron Microscopical (SEM) test was conducted by using Oxford EVO LS15 SEM apparatus (Figure 2), at Faculty of Science, University of Peradeniya, Sri Lanka. Prior to the SEM observation, samples were gold coated to increase the conductivity.

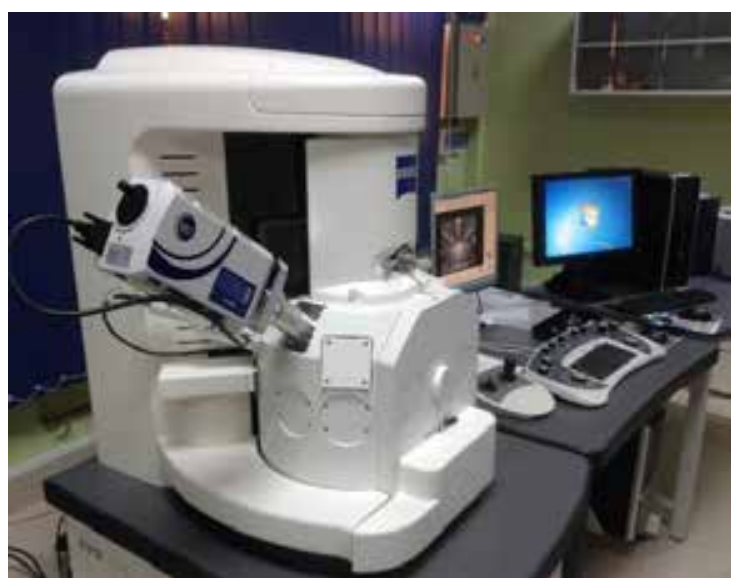

Figure 2- SEM Testing Machine used for the observation

\section{Results and Discussion}

\subsection{XRD test results}

The composition of the OPC based well cement (OPC with sulphate resistance) was obtained from XRD test. Table 1 shows the composition of OPC based well cement obtained from XRD test and typical composition of API class G cement.

Table 1- Chemical Composition of OPC based well cement and API class G cement

\begin{tabular}{|c|c|c|}
\hline Constituents & $\begin{array}{c}\text { OPC based } \\
\text { well } \\
\text { cement (\%) }\end{array}$ & $\begin{array}{c}\text { API class G } \\
\text { cement (\%) } \\
\text { [2] }\end{array}$ \\
\hline $\mathrm{CaO}$ & 64.40 & 64.7 \\
\hline $\mathrm{SiO}_{2}$ & 20.38 & 22.91 \\
\hline $\mathrm{Fe}_{2} \mathrm{O}_{3}$ & 3.26 & 4.75 \\
\hline $\mathrm{Al}_{2} \mathrm{O}_{3}$ & 4.79 & 3.89 \\
\hline $\mathrm{MgO}_{2} \mathrm{~S}$ & 0.98 & 1.8 \\
\hline $\mathrm{SO}_{3}$ & 2.21 & 0.74 \\
\hline $\mathrm{K}_{2} \mathrm{O}$ & 0.04 & 0.64 \\
\hline $\mathrm{Na}_{2} \mathrm{O}$ & - & 0.1 \\
\hline
\end{tabular}

For the construction of injection wells, API class $\mathrm{G}$ cement is most preferable and widely used due to its suitability for high depths, high pressure/temperature conditions and high sulphate resistance.

Based on Table 1, it can be seen that the composition of OPC based well cement is similar to API class G cement. Therefore, it can be concluded that OPC can be used instead of API class $G$ cement for the construction of injection wells.

\subsection{Variation of UCS and Young's modulus with salinity and ageing}

The variation of average UCS of OPC based well cement with curing period is shown in Figure 3. The control point (zero curing period) of Figure 3 was obtained from UCS result of control samples that were oven cured for 24 hours and then were allowed to cool down for 6 hours in the atmosphere. Immediately after 6 hours, they were subjected to UCS testing. At the same time (after 6 hours in the atmosphere), other samples were immersed into the containers containing brine. It should be noted that the curing period mentioned in the article is the total time period that the samples were immersed in various brine contents $(0-30 \%)$. The average UCS of control sample was $29.4 \mathrm{MPa}$. It can be seen that initially the strength of the OPC cement in brine concentrations increases with the ageing period up to 14 days and then it decreases towards 45 days. The increment varies from $42 \%$ - $60 \%$ depending on the salinity up to 14 days. This initial increment is because of the dominant hydration process [2]. However, after a certain period (approximately 14 days), continuous ageing in brine solution causes the reduction of strength and the reduction percentage varies from $4.7 \%-10.6 \%$ for different salinity levels. This is because of the $\mathrm{Ca}^{2+}$ ions in Calcium Silica Hydrate (C-S-H) getting precipitated with $\mathrm{Cl}^{-}$ions[9] as shown in the Equation 1.

$\mathrm{Ca}^{2+}{ }_{(\mathrm{aq})}+\mathrm{Cl}^{-}(\mathrm{aq}) \longrightarrow \mathrm{CaCl}_{2(\mathrm{~s})}$

In continuous aging of brine, $\mathrm{Na}^{+}(\mathrm{aq})$ in the solution is partly adsorbed on the C-S-H surface and this brings about the decrease of $\mathrm{Ca} / \mathrm{Si}$ mol ratio (i.e)and causes the dispersion of $\mathrm{Ca}^{2+}$ ions from C-S-H and those ions get precipitated with available chloride ions [9]. On the other hand, samples immersed in $0 \% \mathrm{NaCl}$ (pure water) does not show any significant amount of decrement in compressive strength as strength variation is caused only due to hydration process.

The variation of UCS with salinity level of the samples immersed for different curing periods 
is shown in Figure 4. Based on Figure 4, it is clear that the uniaxial compressive strength decreases with salinity level for all the curing periods. This strength decrement is because of the retardation in the degree of hydration. When the brine concentration increases, there is a retardation in hydration process i.e. salt content affects the $\mathrm{Ca}(\mathrm{OH})_{2}$ formation.

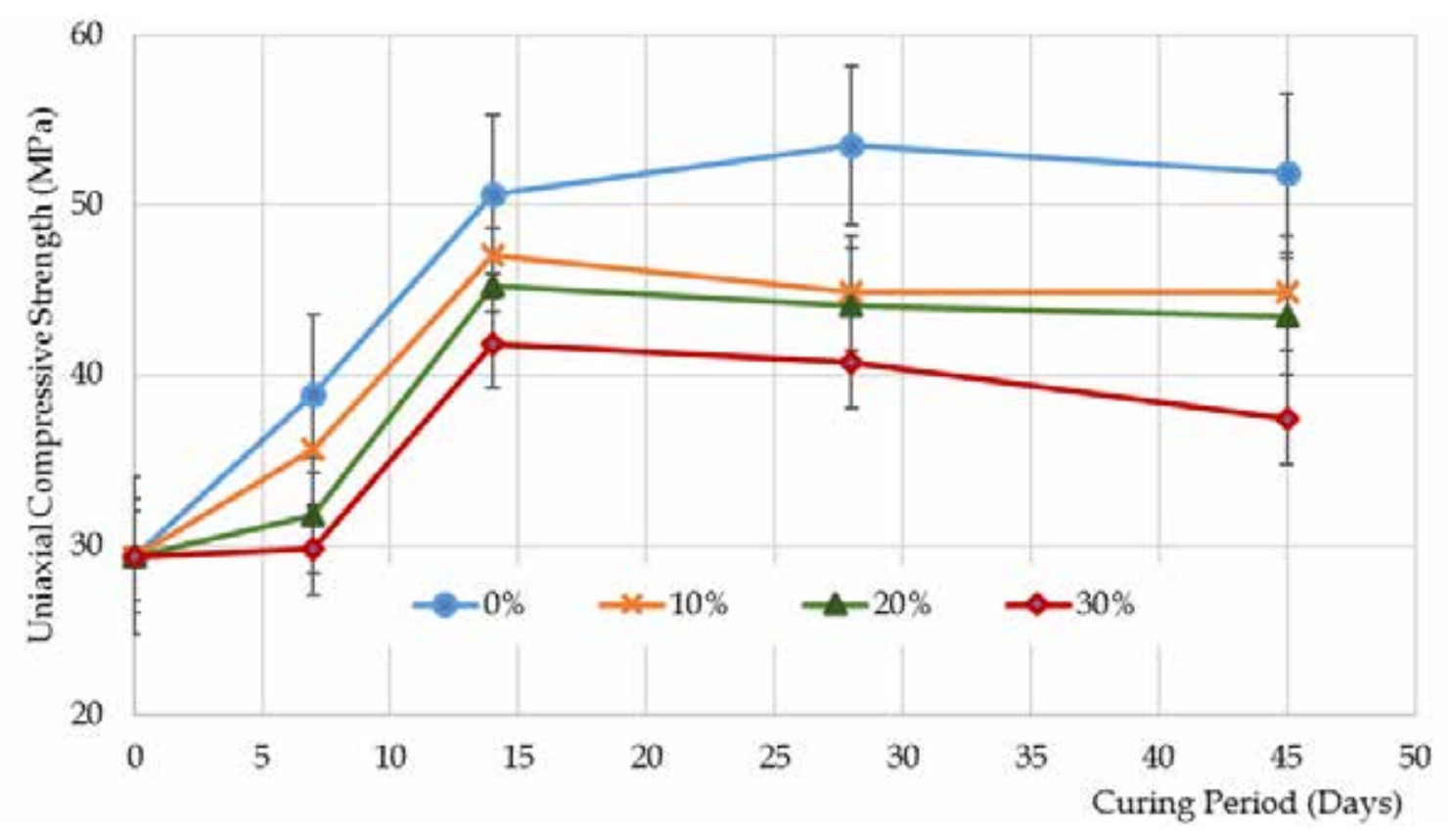

Figure 3 -Variation of Uniaxial compressive strength with curing period

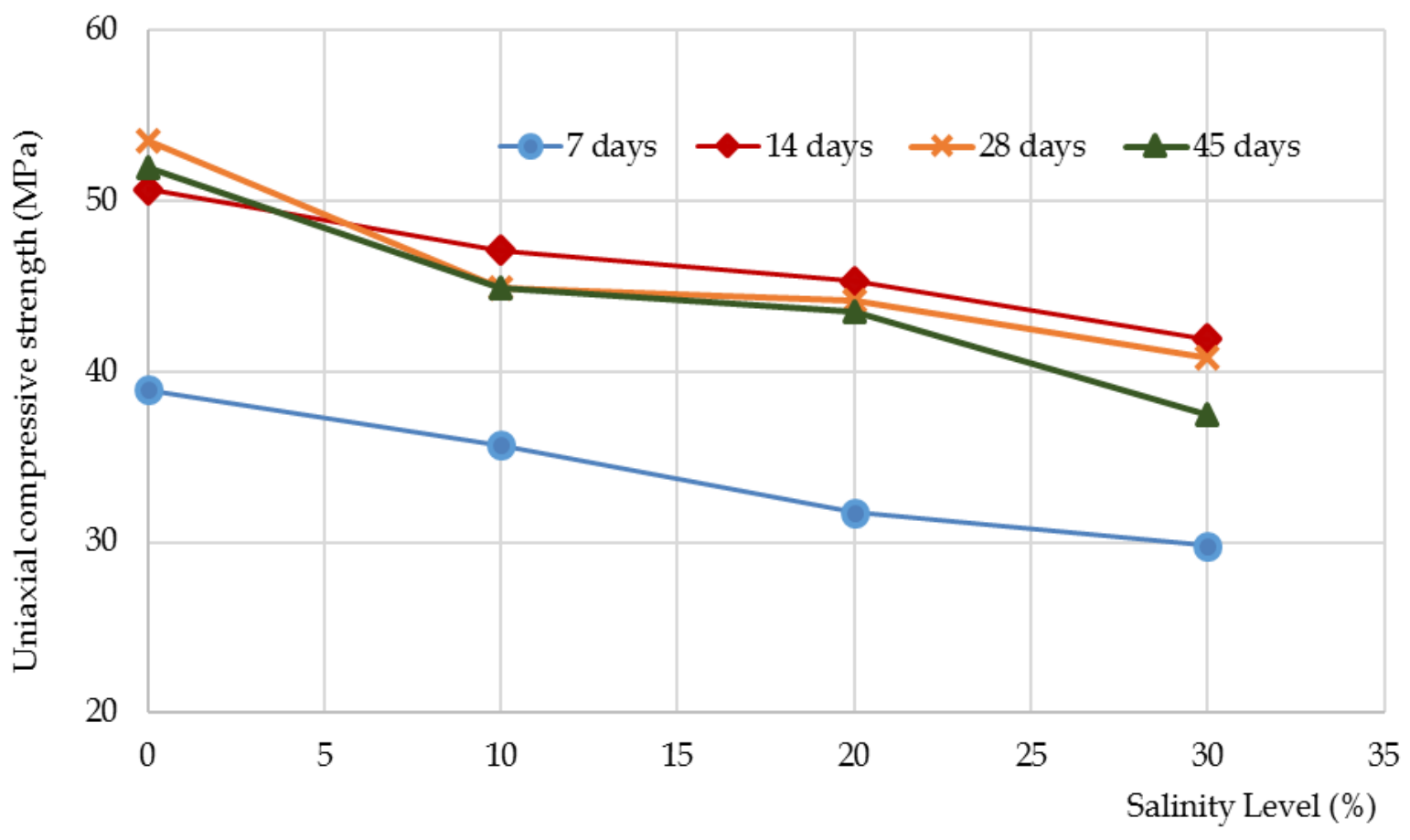

Figure 4 -Variation of Uniaxial compressive strength with salinity level 
In detail, $\mathrm{NaCl}$ is dispersed in C-S-H and $\mathrm{Ca}(\mathrm{OH})_{2}$ in the form of solid solution or microcrystallite precipitation and lowers the activation energy for the decomposition of $\mathrm{Ca}(\mathrm{OH})_{2}$. In addition, salt content affects the interface bonding between $\mathrm{Ca}(\mathrm{OH})_{2}$ and $\mathrm{CSH}$ $[2,9]$. As a result, uniaxial compressive strength of well cement tends to reduce. In addition, it can be seen that 7 days UCS for all the brine contents $(0-30 \%)$ is much lower than that of other curing periods $(14,28 \& 45$ days). This might be due to the partial hydration process i.e. high strength can be obtained only after the complete hydration process. Average stress strain behaviour of the brine immersed samples were obtained from UCS testing and the stress with strain behaviour of well cement is shown in Figure 5. Young's modulus of the cement samples were calculated based on these stress strain plots. Stress - strain plots were derived from the load - displacement relationship obtained according to EN 12390-13 standard by using the displacement transducer which is attached with UCS testing apparatus. As sulphate resistant cement samples are highly brittle, it was difficult to obtain the plastic region of the stress - strain curve. Based on Figure 5, Young's modulus of the samples in each condition was determined. In addition, Young's modulus of the dry sample was obtained as $0.97 \mathrm{GPa}$. The behaviour of Young's modulus of OPC based well cement with ageing period and salinity levels are shown in Figure 6 and Figure 7 respectively. According to Figure 6, Young's Modulus under each concentration initially increases and then decreases with the curing periods. For each immersion duration, Young's modulus decreases with salinity level according to Figure 7 and this is similar to variation of UCS of the samples. This means stiffness of the cement decreases with the increase of brine content.

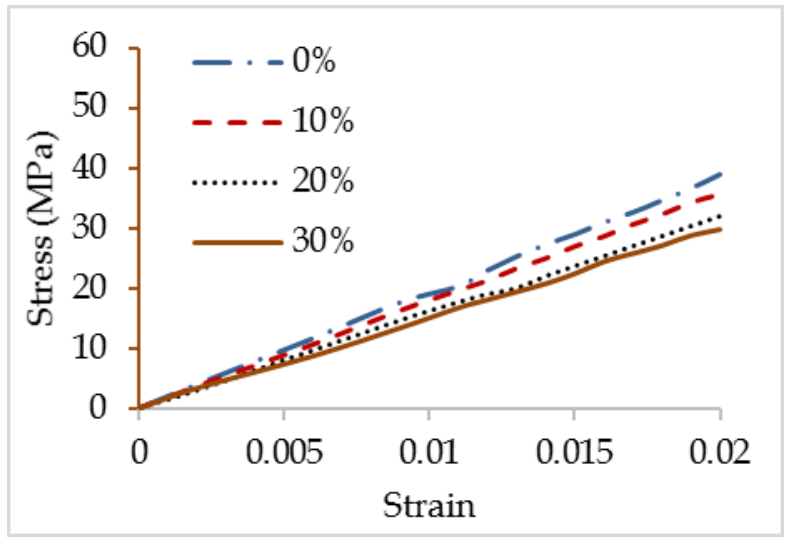

(a)

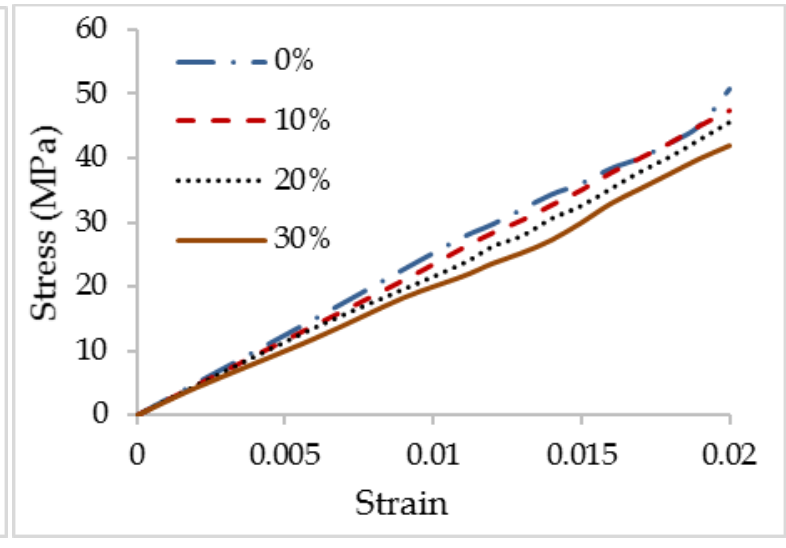

(b)

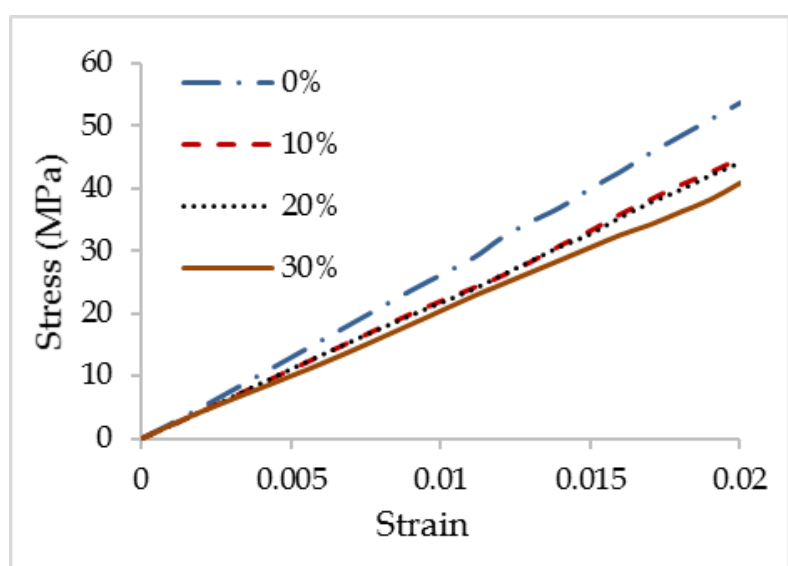

(c)

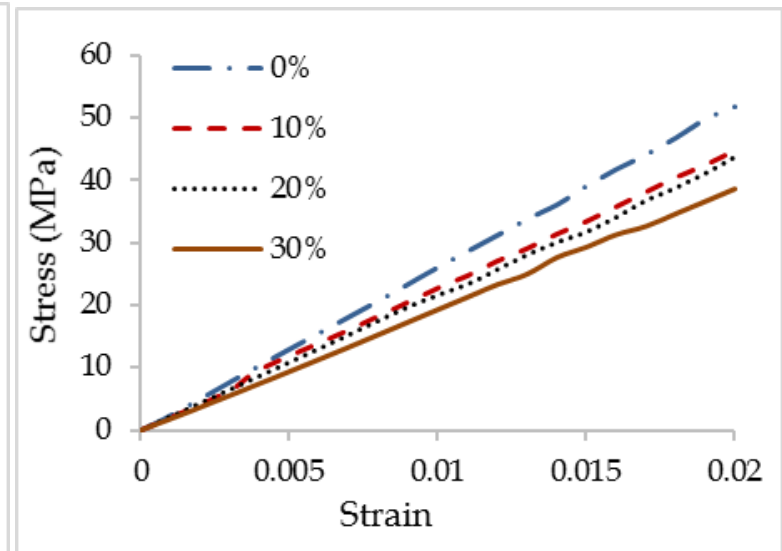

(d)

Figure 5 -Stress-Strain Behaviour of the samples Cured for (a) 7 days, (b) 14 days, (c) 28 daysand (d) 45 days 


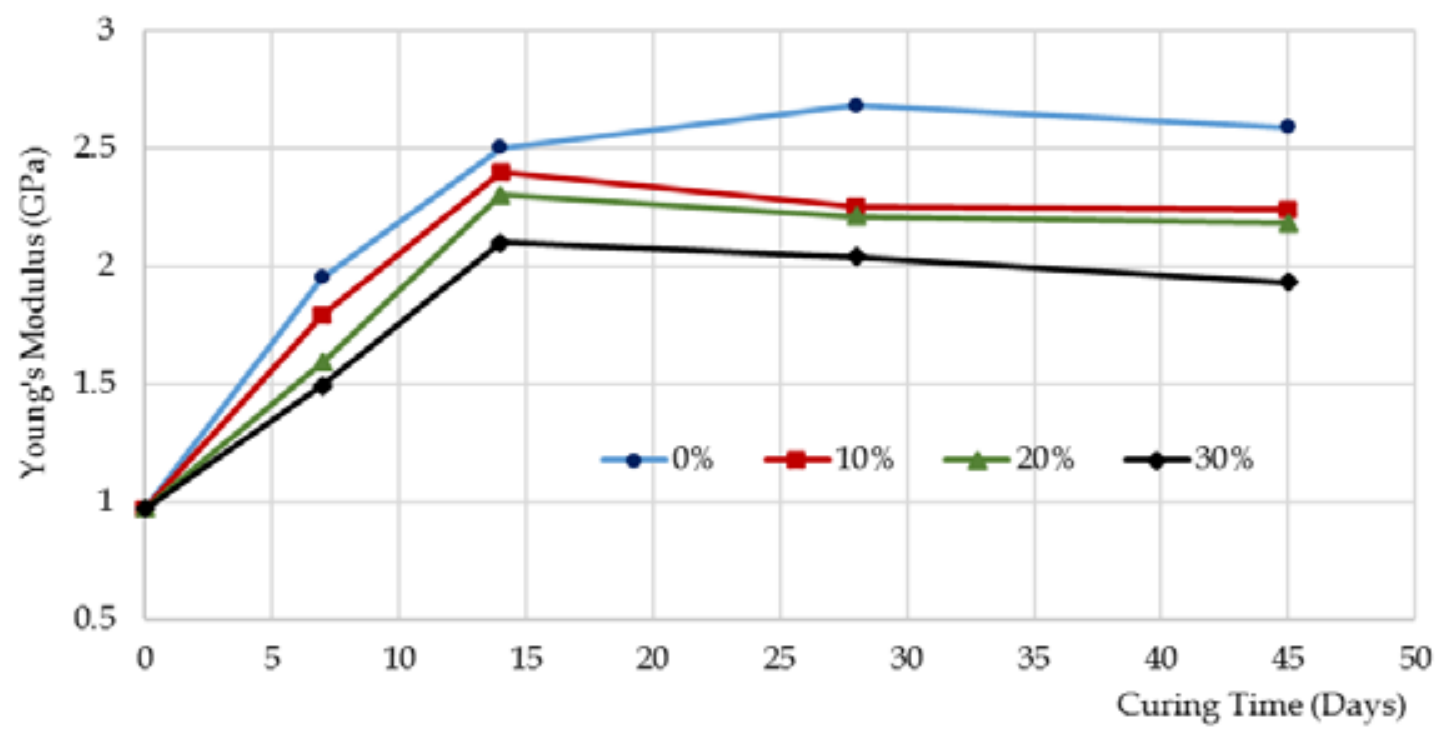

Figure 6 -Variation of Young's Modulus with curing periods

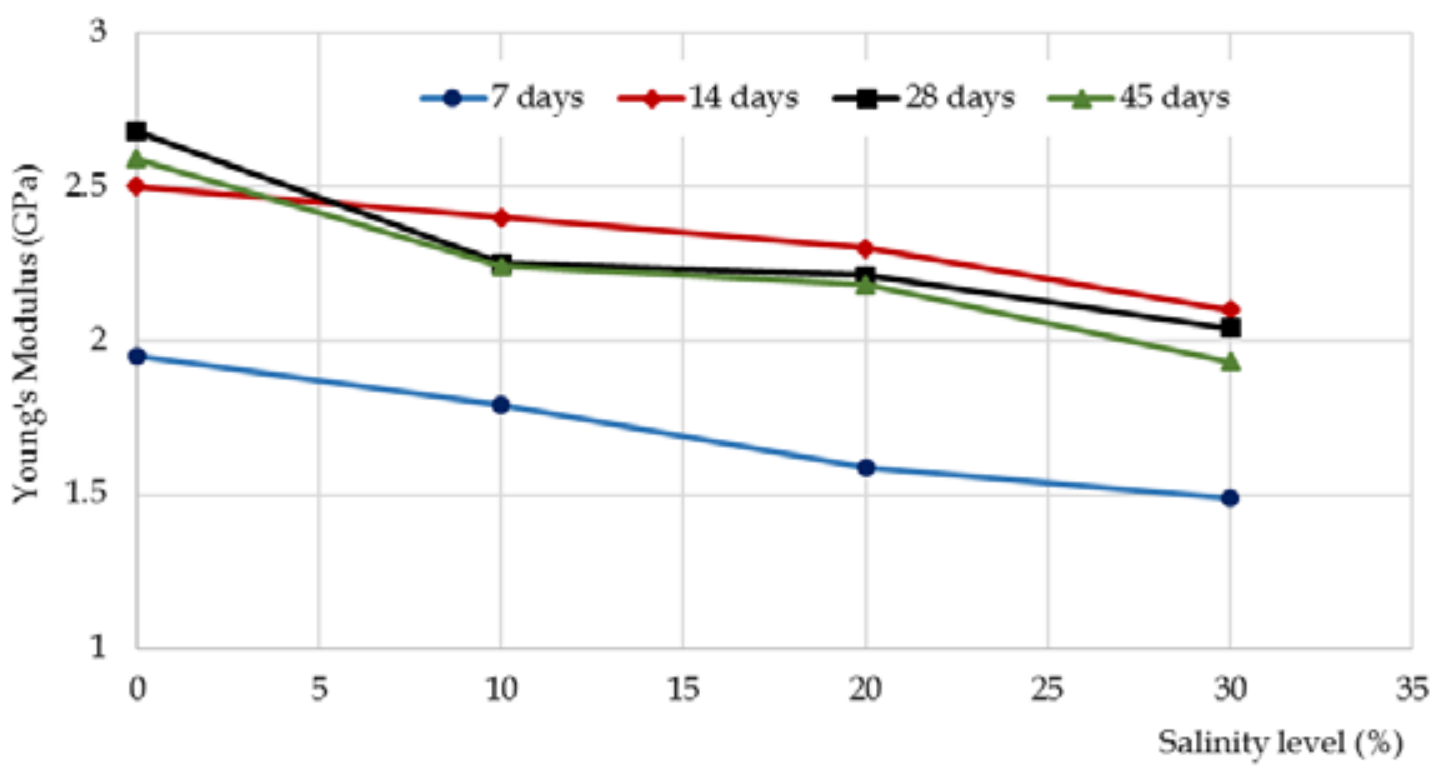

Figure 7 -Variation of Young's Modulus with salinity levels

Young's Moduli of these samples are relatively low and similar results have been obtained in previous studies [11] as well. This is because in both these studies well cement paste samples were used without any fine or course aggregates. This is the reason for the low Young's modulus values observed in the present study.

\subsection{SEM results}

SEM observation was conducted to identify the microstructural variation and appearance of the samples cured under different curing conditions. The SEM image of the dry cement sample (before immersing into brine solutions) is shown in Figure 8. Unreacted cement particles can be seen in the cement sample as indicated in Figure 8 [12].

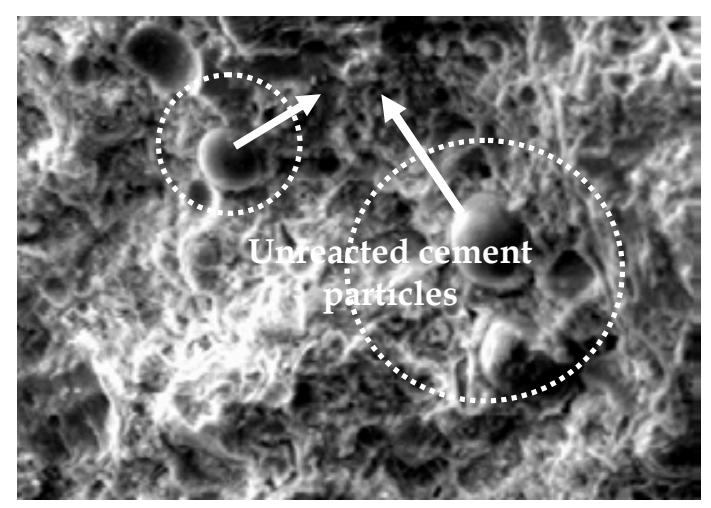

Figure 8 - Microscopical observation of dry sample

Table 2 shows the microstructural variations and appearance of the samples under different curing conditions. Samples cured under 
different conditions shows different microstructural characteristics.

Samples for the SEM test were extracted from locations 5 - $15 \mathrm{~mm}$ from the outer surface of the cement sample. This location was selected as it has been found that propagation fronts $\left(\mathrm{KCl}, \mathrm{NaCl}, \mathrm{CaCl}_{2}\right.$, etc. $)$ start at the surface and it takes 3 months for these fronts to move to the centre [10]. Hence, to capture any reaction between the cement and brine, this location was selected.

Generally, the microstructure of the samples varies due to hydration process. Microstructural changes related to hydration process can be observed from the samples cured in pure water $(0 \% \mathrm{NaCl})$ for 7 and 45 days (A \& B of Table 2). Presence of $\mathrm{NaCl}$ affects the microstructure of the cement and behaviour of the cement as well ( $\mathrm{C}$ and $\mathrm{D}$ of Table 2). However, the effect of $\mathrm{NaCl}$ is mostly dominantly exposed at long term curing as can be seen from $\mathrm{D}$ of Table 2. With the help of Energy-Dispersive X-Ray Spectroscopy (EDX) analysis shown in Figure 9, it was ensured that the white colour crystal forms (D of Table 3) are $\mathrm{CaCl}_{2}$ solid deposits as explained in Equation 1, due to the presence of $\mathrm{Cl}^{-}$ions in brine. It shows that in continuous curing in brine solution, $\mathrm{Cl}^{-}$ ions penetrates through the cement samples and get deposited with $\mathrm{Ca}^{2+}$ ions in between the cement matrix and causes the degradation of the cement samples. Because of this degradation process by $\mathrm{Cl}^{-}$ions, the compressive strength decreases with the increasing of brine concentration and with increasing of curing time as well.

Table 2 -Microstructural observation of brine cured samples

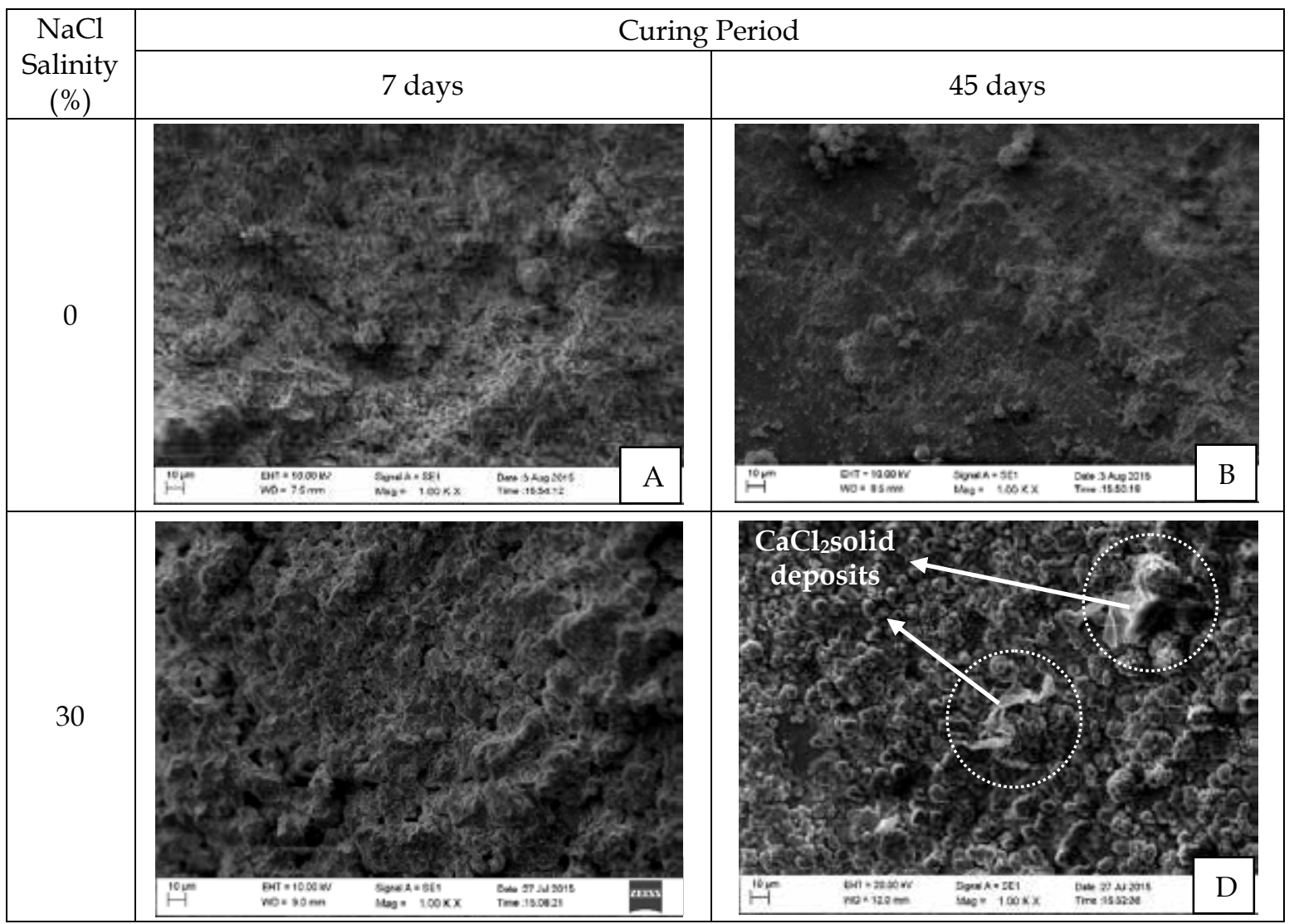




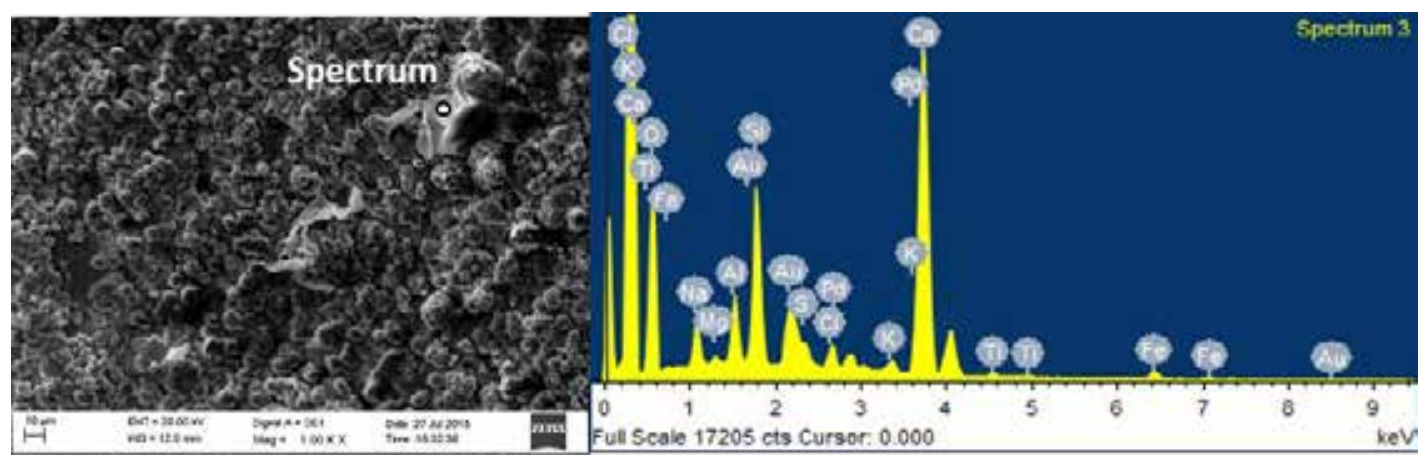

Figure 9 -Energy dispersive X-Ray spectroscopy analysis result for sample cured for 45 days in $30 \%$ $\mathrm{NaCl}$

\section{Conclusions}

An experimental study was conducted to predict the mechanical behaviour of well cement cured in brine $(0-30 \% \mathrm{NaCl})$ for different curing periods (0-45 days). The following sections brief the conclusions made from this study.

Ordinary Portland Cement (OPC) with sulphate resistance satisfies the requirement of API Class G cement. Therefore, OPC with sulphate resistance can be used instead of API class $G$ cement for the construction of injection wells. Strength and the Young's modulus of OPC samples reduce with increase in salinity levels and this is due to the retardation in the hydration process with increase in salinity. In addition, the strength and Young's modulus of the cement samples cured in brine increases initially up to 14 days and then decreases beyond 14 days. This is because initially the hydration process is dominant but in continuous ageing the samples get degraded because of the presence of $\mathrm{NaCl}$. This result was further supported by observing the microstructural variations by using Scanning Electron Microscope (SEM) and ensured that the above behaviour of OPC is due to the reaction between the cement and $\mathrm{Cl}^{-}$ions in brine.

On the whole, concentration of brine solution plays an important role in physical and chemical changes in well cement. Therefore, effect of saline water is a very important factor that should be considered seriously for the construction of $\mathrm{CO}_{2}$ injection wells and oil and gas wells.

\section{References}

1. Nasvi, M. C., Ranjith, P., Gamageb, A., Sanjayan, J., Mechanical Properties of Geopolymer Cement in Brine: Its Suitability as Well Cement for Geological Sequestration of Carbon Dioxide $\left(\mathrm{CO}_{2}\right) .7$ th Asian Rock Mechanics Symposium, 2012.

2. Lecolier, E., Rivereau, A., Saout, G. L., Audibert, H. A., Durability of Hardened Portland Cement Paste used for Oilwell Cementing. Oil \& Gas Science and Technology. 62 (3): 335-345, 2007.

3. Bachu, S., Bennion, D. B., Experimental Assessment of Brine and/or $\mathrm{CO}_{2}$ Leakage through Well Cements at Reservoir Conditions, International Journal of Greenhouse Gas Control, 3: 494-501, 2009.

4. Bruant, R., Guswa, A., Celia M, Peters C., Safe Storage of $\mathrm{CO} 2$ in Deep Saline Aquifers. Environmental science \& technology, 36, 240A245A, 2009.

5. Luke, C., Deasy, H., Lupton, N., Integrity of Wellbore Cement in CO2 Storage Wells State of the Art Review. Australian National Low Emissions Coal Research \& Development Project 3: 1110-0084, 2012.

6. Runar, N., Well Design and Well Integrity. Wabamun Area $\mathrm{CO}_{2}$ Sequestration Project, 2010.

7. Barlet, G. V., Rimmele, G., Porcherie, G., Quisel, N., Desroches, J., A Solution against Well Cement Degradation under $\mathrm{CO}_{2}$ Geological Storage Environment. International journal of Greenhouse Gas Control. 3: 206 - 216, 2009.

8. Arina, B. S., Sonny, I., Effects of Pressure and Temperature on Well Cement Degradation by Supercritical $\mathrm{CO}_{2}$. International Journal of Engineering \& Technology IJET-IJENS. 10 (04), 53-61, 2012.

9. Xingshan, Z., Xian, L., Mingjiang, H., Ying, Z., The Hydration of Saline Oil-Well Cement. Cement and Concrete Research. 26 (12): 1753-1759, 1996.

10. Nadine, N., Lecolier, E., Aouad, G., Rivereau, A., Damidot, D., Chimie, C.R., Effect of Curing Conditions on Oilwell Cement Paste Behaviour during Leaching. Experimental and Modelling Approaches. 12: 511-520, 2009.

11. Nasvi, M.C., Ranjith, P., Sanjayan, J., Comparison of Mechanical Behaviour of 
Geopolymer and Class G Cement as Well Cement at Different Curing Temperatures for Geological Sequestration of Carbon dioxide. $46^{\text {th }}$ Rock Mechanics/ Geo mechanics Symposium, 2012.

12. Sindhunata, Van, D.J.S., Lukey, G.C., Xu, H., Effect of Curing Temperature and Silicate Concentration on Fly Ash Based Geopolymerization. Ind. Eng. Chem. Res. 45: 3559-3568, 2006 